International Journal of Engineering, Science and Technology

Vol. 2, No. 11, 2010, pp. 41-49
INTERNATIONAL

JOURNAL OF

ENGINEERING,

SCIENCE AND

TECHNOLOGY

Www.ijest-ng.com

(C) 2010 MultiCraft Limited. All rights reserved

\title{
Influence of process parameters on the cup drawing of aluminium 7075 sheet
}

\author{
G. Venkateswarlu, M. J. Davidson and G. R. N. Tagore \\ Department of Mechanical Engineering, National Institute of Technology, Warangal, Andhrapradesh, INDIA—506004 \\ Email:ganta_hmp@rediffmail.com
}

\begin{abstract}
AA7075 is one of the most important structural materials extensively used in automobile and aerospace industries. Extensive research on its formability aspects is required to develop useful components of complex shapes out of this material. One of the ways to measure the formability is to find its deep drawability characteristics. In this study, the significance of three important deep drawing process parameters namely blank temperature, die arc radius and punch velocity on the deep drawing characteristics of aluminium 7075 sheet was determined. The combination of finite element method and Taguchi analysis was used to determine the influence of process parameters. Simulations were carried out as per orthogonal array using DEFORM 2D software. Based on the predicted deformation of deep drawn cup and analysis of variance test (Anova), it was observed that blank temperature has greatest influence on the formability of aluminium material followed by punch velocity and die arc radius. Multiple regression analysis techniques were applied in modelling the behaviour of AA 7075 aluminium alloy under multistep deformation conditions.
\end{abstract}

Key words: Formability, Deep drawing, Taguchi, ANOVA, MRA.

\section{Introduction}

Most of the automobile industries use sheet metal forming to produce automobile body parts. In sheet metal forming, a thin blank sheet is subjected to plastic deformation using forming tools to get the desired shape. The deformation temperature, die arc radius, punch velocity, blank holder pressure, coefficient of friction etc greatly influences the formability of aluminium. Hence, it is essential to determine the degree of influence of process parameters on the formability in order to optimize appropriate conditions to maximize the formability. The process parameter of blank temperature opens up the possibility of significantly improving the ductility of the material and the associated forming capacity. On the other hand, it also offers the possibility of significantly reducing the yield point that helps in reduction of the forming forces and pressures. Shehata et al. (1978) and Wilson et al. (1988) demonstrated that the formability can be improved using differential temperature rather than a uniform temperature rise. Finch et al. (1946) investigated the effect of warm forming on drawbility of both rectangular and circular cups from annealed and hardened aluminum sheet alloys. The results indicated significant improvement in the drawability (in terms of cup height) at a relatively moderate temperature of about $150{ }^{\circ} \mathrm{C}$ even for the precipitation hardened alloys (like 2024-T4 and 7075-T6). Takuda et al. (2002) confirmed that considerable formability is attained when the cups were deep drawn at elevated temperatures. Toros et al. (2008) concluded that warm forming is beneficial for formability and the alloys of aluminiun and magnesium show good formability at temperatures ranging from 200 to $300{ }^{\circ} \mathrm{C}$. They developed an analytical model to evaluate deep drawing process at elevated temperatures and under different blank holder pressure (BHP) and identified that blank temperature; punch speed, BHP, and friction are the main factors that influence formability.

Huang et al. (1995) carried out theoretical and experimental analysis on the influence of die arc on the formability of cylindrical cup drawing process . They concluded that larger formability could be obtained when the cup is deep drawn with largest die arc. Harpel et al. (2000) presented a numerical prediction for determining formability of aluminium sheet and concluded that the formability decreased as the die profile radius decreased. Dejmal et al. (2002) found optimal die curvature to determine high formability and stated that the optimal curvature varies with the interfacial friction (mf), with the material strain hardening (n), with the drawing ratio (DR), but not with the blank thickness. Rao et al. (2010) mentioned that the conical die with smooth entry 
by providing radius avoids strain concentration around the sharp angle for the conventional die shapes for the initial stroke values but the strain is somewhat evenly distributed at large strokes The strain is more evenly distributed around the corner right from the beginning of the stroke. Tetsuo et al. (1999) investigated the effect of forming speed and the temperature on the deep drawability of Al-Mg alloy sheet by performing cylindrical deep drawing tests at the various forming speeds and at the various die temperature rates. They found that the formability increased with increasing die temperature and it lowered with increased forming speed at all temperatures. The aluminium alloy 7075 is one of the most important engineering alloys .It has been widely used as structural material in the transport applications, including marine, automotive and aviation applications due to their attractive properties, such as low density, high strength, ductility, toughness and resistance to fatigue (Heinz et al., 2000; Williams et al., 2003; and Li et al., 2008). These high strength alloys are desirable to reduce the weight and cost but lacks in formability. However, the enhancement of the formability of this material is a big challenge. There has been little research on the influence of process parameters on formability behaviour of 7075 aluminum alloy. In present study, the effect of blank temperature, die arc radius and punch velocity on formability of 7075 aluminum alloy thin sheet was investigated.

In this present work, a statistical approach based on Taguchi and Anova techniques was adopted to determine the degree of importance of each of the process parameter on the formability of deep drawn cup. Taguchi method has been applied by several researchers in forming studies to design the experiments and to determine the influence of process parameters on the formed cups. Davidson et al. (2008) used Taguchi method to optimize flow-forming process for maximum deformation of the formed tube. The surface roughness of the flow-formed tube was predicted by Davidson et al. (2008) using response surface methodology. The age hardening behaviour of thin walled tubes for various aging temperature, time and solutionizing temperature was successfully studied and predicted by Davidson et al. (2008) using response surface methodology. Elangovan et al. (2010) studied the influence of the diameters of perforations and ligament widths on the forming limit strains. It was observed that the forming limit strains were increased with the ligament width and decreased with diameter of perforations. In this study, Taguchi analysis and FEA study have been performed to analyze the cup drawing process and to develop a regression equation.

\section{Methodology}

The formability of a blank sheet depends on the process parameters such as blank temperature, punch radius, die arc radius, diepunch clearance, punch velocity, mechanical properties, thickness of sheet metal and the parts geometry. Previous research work by the authors (2010) on the formability of aluminium emphasized the role of temperature in forming of deep drawn cup. An appropriate die radius allows smooth flow of materials on one hand and reduces material wastage on the other hand. Similarly, the punch speed condition enhances the flow of material in to the die cavity. The quality of the formed part is determined by the degree of influence of these process parameters in the sheet metal forming. In addition to the blank temperature and die radius, punch velocity also influences the metal flow into the die cavity in the deep drawing process. The objective of this investigation is to maximize the formability. Hence, in the present investigation, an attempt has been made to study the effect of above mentioned important process parameters, namely blank temperature, die arc radius and punch velocity on the formability of AA 7075 through simulation experiments.

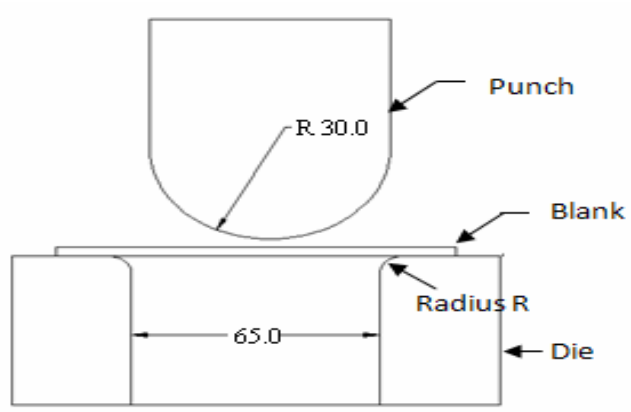

Figure 1: Tools used in the simulations

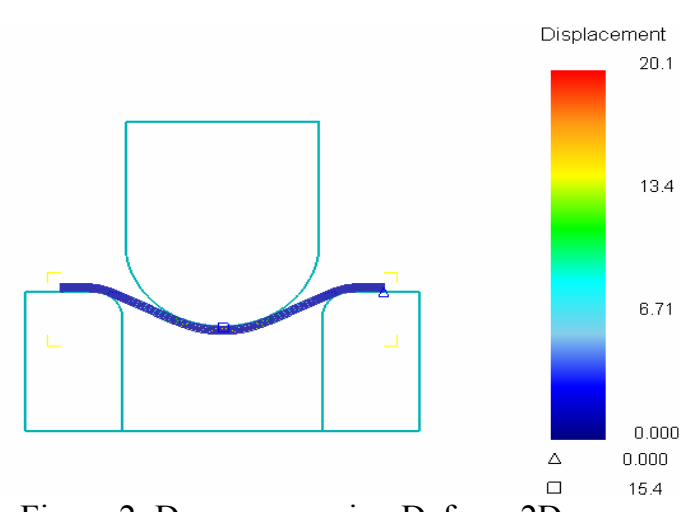

Figure 2: Drawn cup using Deform-2D

To this end, cylindrical cup drawing simulations were carried out with a tool set of dimensions given in Figure 1. A drawn cup using DEFORM 2D is shown in Figure 2. All the simulations were performed as per Taguchi orthogonal array as shown in the Table 2. Blank of diameter $102 \mathrm{~mm}$ with $3 \mathrm{~mm}$ thickness of AA 7075 was taken and it was constrained at $\mathrm{X}$ and $\mathrm{Y}$ directions. Simulations were performed using Deform-2D and the damage behaviour of defect free cups was evaluated using Cockcroft \& Latham algorithm. The elastic properties of material are Young's modulus $\mathrm{E}=70 \mathrm{GPa}$ and Poisson ratio=0.3and the hardening parameters are: strength coefficient $\mathrm{K}=827 \mathrm{MPa}$ and the strain-hardening exponent $\mathrm{n}=0.11$.

Dr. Genichi Taguchi developed the Taguchi techniques. Taguchi developed the foundations of robust design and validated its basic philosophies by applying them in the development of many products (Phadke, 1989).Using Taguchi method, a balanced comparison of levels of the process parameters and significant reduction in the total number of required simulations can both be 
achieved. The Taguchi technique places a great deal of importance on the reduction in variability of products and processes. Improved robustness can often be achieved without major capital expenditure with these techniques (1987). Mathivanan et al. (2010) studied the influence of injection moulding variables on sink marks using Taguchi techniques and optimized process parameters. Moshat et al. (2010) used entropy measurement technique combined with grey Taguchi method to optimize CNC milling parameters. Moshat et al. (2010) proposed a PCA-based Taguchi multi optimization technique to optimize process parameters of $\mathrm{CNC}$ milling process parameters. In this investigation, Taguchi experimental design with three levels of process parameters was used to plan numerical simulations.

Table 1: Process parameters and their levels

\begin{tabular}{|l|c|c|c|}
\hline \multirow{2}{*}{ Process parameter } & \multicolumn{3}{|c|}{ Levels and Their range } \\
\cline { 2 - 4 } & $\mathbf{1}$ & $\mathbf{2}$ & $\mathbf{3}$ \\
\hline Blank temperature $\left(\mathrm{T},{ }^{0} \mathrm{C}\right)$ & 200 & 325 & 450 \\
\hline Die arc radius $(\mathrm{R}, \mathrm{mm})$ & 6 & 9 & 12 \\
\hline Punch velocity $(\mathrm{V}, \mathrm{mm} / \mathrm{s})$ & 1 & 2 & 3 \\
\hline
\end{tabular}

Table 2: Orthogonal array $\left(\mathrm{L}_{9}\right)$ of Taguchi method

\begin{tabular}{|c|c|c|c|}
\hline \multirow{2}{*}{ Expt. } & \multicolumn{3}{|c|}{ Parameter } \\
\cline { 2 - 4 } & Blank Temperature & Die arc radius & Punch velocity \\
\hline 1 & 1 & 1 & 1 \\
\hline 2 & 1 & 2 & 2 \\
\hline 3 & 1 & 3 & 2 \\
\hline 4 & 2 & 1 & 3 \\
\hline 5 & 2 & 2 & 1 \\
\hline 6 & 2 & 3 & 3 \\
\hline 7 & 3 & 1 & 1 \\
\hline 8 & 3 & 2 & 2 \\
\hline 9 & 3 & 3 & \\
\hline
\end{tabular}

There are many factors, both process and material parameters that influence the deep drawing process. In this study, AA 7075 sheet was deep drawn to determine the formability characteristics. Among all process parameters, blank temperature, die arc radius and punch velocity play an important role in the formability of aluminium material and hence the above parameters were considered in this study. The levels are selected based on the process window. Other process parameters such as die temperature $\left(25^{\circ} \mathrm{C}\right)$, punch radius $(30 \mathrm{~mm})$, coefficient of friction $(0.3)$ etc were fixed in the simulation. Table 1 shows the chosen parameters and their levels used in the finite element (FE) simulations. The higher orders interactions among the above factors are assumed to be negligible and the information on the main effects can be obtained by running $3^{3}=27$ experiments. The appropriate Taguchi orthogonal array for the above parameters with three levels is $\mathrm{L}_{9}$, which requires only nine simulations as shown in Table 2 . After designing the experiments with various combinations of process parameter levels, FE simulations were carried out to predict the deformation behaviour of the aluminium sheet. The results obtained from the FE simulations were treated using statistical approach, namely Anova.

The purpose of using Anova is to determine the parameters that influence the deep drawing process that markedly influence the formability. This will yield the information about the impact of each parameter and the degrees of importance of each parameter in the deformation behaviour of the blank sheet.

\section{Results and discussions}

3.1 Influence of process parameters on the deformation: As seen in Table 3, highest formability was observed in experiment number 8 (most favourable combination of the chosen process parameters), in which the blank was deep drawn at $450{ }^{\circ} \mathrm{C}$ with $9 \mathrm{~mm}$ die arc radius at $1 \mathrm{~mm} / \mathrm{sec}$ punch velocity. In the last set of experiments, higher deformation (drawn cup height) was observed as compared to the remaining cases. With a higher percentage of Mg content in AA 7075, the ductility of AA 7075 at elevated temperatures is found to be higher due to the increasing number of the slip planes in the hexagonal structure of $\mathrm{Mg}$ at elevated temperatures. It is evident that blank temperature has played an important role in the deep drawing process of sheet. In 
experiment number 2 (most unfavourable combination of chosen process parameters), the deformation was very low. The die arc radius and punch velocity also have moderate influence on the enhancement of the formability of aluminium.

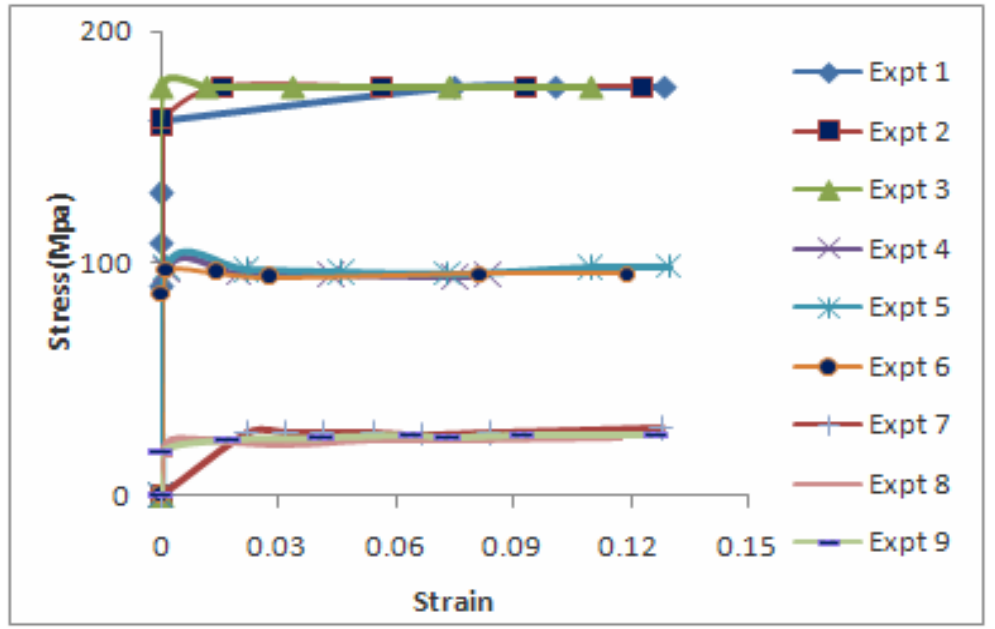

Figure 3: Stress - Strain curve

Figure 3 shows the stress-strain curves for different experiments. The stress and strain values during drawing process were given by software and also a graph through these points is drawn by software as shown above. It indicates that the temperature has significant influence on the yield stress as compared to other parameters such as die arc radius and punch velocity. For metallic materials, most of the plasticity mechanisms are thermally activated resulting in softening of the material and that may result in lowering of stresses at elevated temperatures. In the first three experiments, the lowest punch velocity (Expt.1) reduced the yield stress and subsequently increased the cup height. In the second set of experiments involving experiment numbers 4,5 and 6 , the yield stress drops as the die arc radius increases. It is clearly seen that the experiment number 8 has resulted in lower yield stress, which exhibits excellent formability as compared to the remaining set of experiments.

\subsection{Punch force evaluation:}

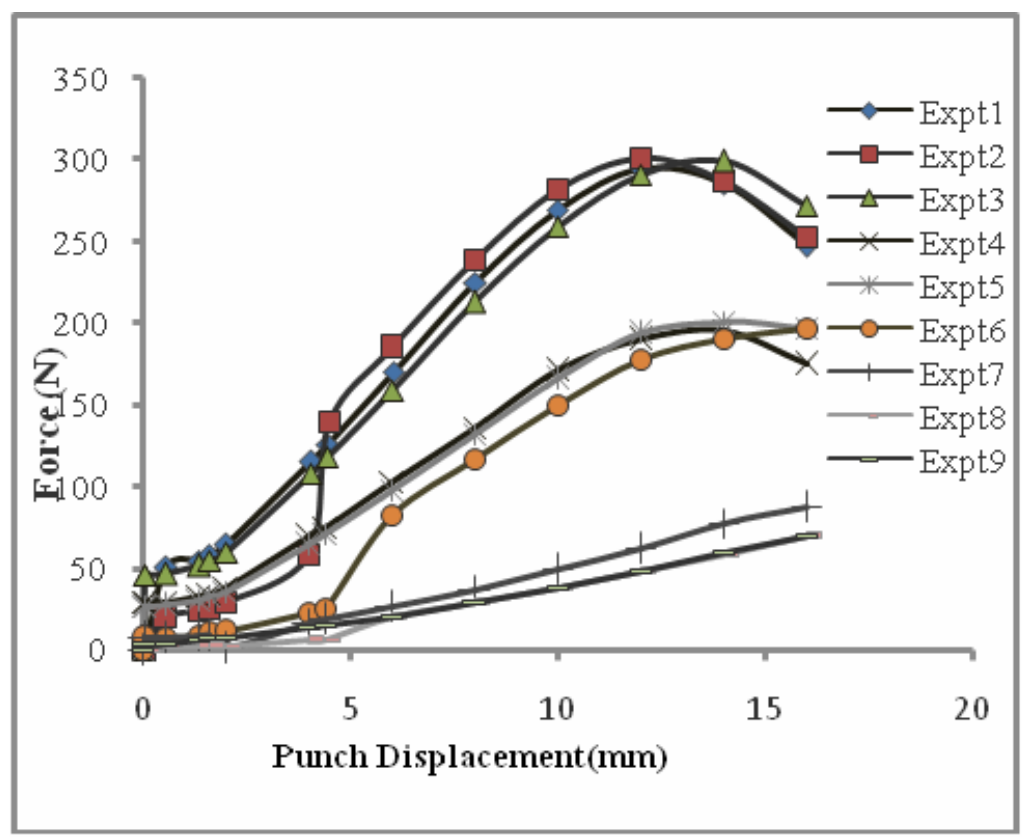

Figure 4: Deformed cup height vs Punch force 
Hot working generally degrades mechanical properties. Hence, even though, forming is rather easy at elevated temperatures, it is not a preferred process as microstructural changes may takes place even after cooling it to room temperature. However, in the case of AA7075, as it is a natural age hardening alloy, heating the alloy closer to $450{ }^{\circ} \mathrm{C}$ will take the alloy closer to the solutionizing temperature. However Natural age hardening process takes. Hence, the ill effect of elevated temperature forming is negated in this alloy. However, literature indicates that this alloy during forming does not undergo recrystallisation after solution or aging treatments. The workability index in 7075 alloys is improved approximately $50 \%$ by over aging. The general problem involved with deformation softening with hot working is localized shear failure before the onset of necking. However in AA 7075, this type of localization in over aged conditions is lower than that of naturally aged condition thus there is small improvement in workability. Figure 4 shows the evolution of punch force on the deep drawing of the axi-symmetric cup versus the punch displacement. Marginal differences in the punch forces were observed between the experiments. In the first three experiments, when the blank temperature was at lowest level, higher punch force was required as compared to the remaining six cases ,due to higher flow stresses. The punch force drops rapidly at experiment number $7\left(450{ }^{\circ} \mathrm{C}\right.$ blank temperature $)$, indicating that flow stress has decreased by heating blank to higher temperature.

3.3 Anova: Anova is a statistical technique for determining the degree of difference or similarity between two or more groups of data. It is based on the comparison of the average value of a common component. In this paper Pareto Anova (1996), which measures the importance of each process parameter in deep drawing process, is used. Pareto Anova is a simplified Anova method, which is based on Pareto principle. The Pareto Anova technique is a quick and easy method to analyze results of the parameter design. The Pareto Anova technique does not need F-test. This technique identifies the important parameters and calculates the percentage influence of each parameter on different quality characteristics. The use of both Pareto Anova technique and S/N ratio approach makes it less cumbersome to analyse the results and hence, make it fast to arrive at the conclusion. Alexandreanu et al (2003) conducted the experiments on effect of grain boundary character distribution on the high temperature distribution behaviour of Ni-16 Cr-9 Fe alloys using statistical analysis of variance and suggested that the hardness in the vicinity of coincident site lattice boundaries (CSLBs), and the grain-averaged hardness increases with fraction of contiguous CSLBs. Keller et al. (2010) conducted TEM study of dislocation patterns near surface and core regions of deformed nickel poly crystals across the cross section using statistical analysis of variance and suggested that a surface effect appears with a decrease of intragranular internal back stress near the free surface independently of the number of grains across the thickness. A better way to compare the sheet metal behaviour to deep drawing is to use the mean squared deviation that combines the effects of both average and standard deviation of the results. In order to increase the robustness of design against noises and to accommodate wide ranging data, Taguchi (1987) recommended a logarithmic transformation of MSD (called the signal to noise ratio) for analysis of the results. When the $\mathrm{S} / \mathrm{N}$ ratio is used for results analysis, the optimum condition identified from such analysis is more likely to produce consistence performance. The deformation of the deep drawing cup was evaluated and presented in Table 3 for simulation experiments as shown in Table 2.

Table 3: ANOVA data

\begin{tabular}{|c|c|c|c|c|c|}
\hline Parameter & Level & $\begin{array}{c}\text { Expt } \\
\text { no. }\end{array}$ & Cup height $(\mathrm{Y}, \mathrm{mm})$ & $\mathbf{S} / \mathbf{N}$ & $\mathbf{S} / \mathbf{N}_{\mathrm{ij}}$ \\
\hline \multicolumn{6}{|c|}{ Blank Temp(T) } \\
\hline & & 1 & 7.05 & 16.9638 & \\
\hline \multirow{3}{*}{ Level 1} & 200 & 2 & 5.83 & 15.3134 & 16.3514 \\
\hline & & 3 & 6.90 & 16.7770 & \\
\hline & & 4 & 6.50 & 16.2583 & \\
\hline \multirow{3}{*}{ Level 2} & 325 & 5 & 6.97 & 16.8647 & 17.7077 \\
\hline & & 6 & 10.00 & 20.0000 & \\
\hline & & 7 & 11.70 & 21.3638 & \\
\hline \multirow{2}{*}{ Level 3} & 450 & 8 & 15.40 & 23.7505 & 22.8004 \\
\hline & & 9 & 14.60 & 23.2870 & \\
\hline \multicolumn{6}{|c|}{ Die Arc Radius(R) } \\
\hline & & 1 & 7.05 & 16.9638 & \\
\hline \multirow{3}{*}{ Level 1} & 6 & 4 & 6.50 & 16.2583 & 18.1953 \\
\hline & & 7 & 11.70 & 21.3638 & \\
\hline & & 2 & 5.83 & 15.3134 & \\
\hline \multirow[t]{3}{*}{ Level 2} & 9 & 5 & 6.97 & 16.8647 & 18.6429 \\
\hline & & 8 & 15.40 & 23.7505 & \\
\hline & & 3 & 6.90 & 16.7770 & \\
\hline \multirow{2}{*}{ Level 3} & 12 & 6 & 10.00 & 20.0000 & 20.0123 \\
\hline & & 9 & 14.60 & 23.2870 & \\
\hline
\end{tabular}


Table 3 (cont'd): ANOVA data

\begin{tabular}{|c|c|c|c|c|c|}
\hline Parameter & Level & $\begin{array}{c}\text { Expt } \\
\text { no. }\end{array}$ & Cup height $(\mathrm{Y}, \mathrm{mm})$ & $\mathrm{S} / \mathbf{N}$ & $\mathbf{S} / \mathbf{N}_{\mathrm{ij}}$ \\
\hline \multicolumn{6}{|c|}{ Punch Velocity(V) } \\
\hline & & 1 & 7.05 & 16.9638 & \\
\hline \multirow{3}{*}{ Level 1} & 1 & 6 & 10.00 & 20.0000 & 20.2381 \\
\hline & & 8 & 15.40 & 23.7505 & \\
\hline & & 2 & 5.83 & 15.3134 & \\
\hline \multirow[t]{3}{*}{ Level 2} & 2 & 4 & 6.50 & 16.2583 & 18.2862 \\
\hline & & 9 & 14.60 & 23.2870 & \\
\hline & & 3 & 6.90 & 16.7770 & \\
\hline \multirow{3}{*}{ Level 3} & 3 & 5 & 6.97 & 16.8647 & 18.3352 \\
\hline & & 7 & 11.70 & 21.3638 & \\
\hline & & & & $\frac{\bar{S}}{N}=18.9532$ & \\
\hline
\end{tabular}

The $\mathrm{S} / \mathrm{N}$ ratio is used to measure the deformation deviation. The $\mathrm{S} / \mathrm{N}$ ratio is explained as $-10 \log (\mathrm{MSD})$, where MSD is mean square deviation $\frac{1}{n} \sum_{0}^{n}\left(\frac{1}{Y}\right)$ for the output characteristics; $\mathrm{n}$ is the number of experiments (for one set of parameters, $\mathrm{n}=1$ ) and $\mathrm{Y}$ is the evaluated value of deformed cup height from the simulation experiments.

Model calculation for $\mathrm{S} / \mathrm{N}$ ratio for first experiment $\left(\mathrm{T}=200{ }^{\circ} \mathrm{C}\right)$ :

$$
\begin{aligned}
& \mathrm{MSD}=\frac{1}{n} \sum_{0}^{n}\left(\frac{1}{{ }^{2}}\right)=\frac{1}{1} \sum_{0}^{1}\left(\frac{1}{7.05}\right)=0.02012 . \text { Here, } \mathrm{n}=1 \text { and } \mathrm{Y}=7.05 \\
& \mathrm{~S} / \mathrm{N} \text { ratio }=-10 \log (0.02012)=16.9638
\end{aligned}
$$

The overall mean S/N ratio is expressed as $\frac{\bar{S}}{N}=\frac{1}{9} \sum_{1} \frac{S}{N_{i}}=18.9532$

The sum of squares due to variation about overall mean is $S S=\sum_{i=1}^{9}\left(\frac{S}{N_{i}}-\overline{\left(\frac{S}{N}\right)}\right)^{2}$

The calculated value for this expression is 27.343 . For the $\mathrm{i}^{\text {th }}$ process parameters, the sum of squares due to variation about is

$$
S S_{i}=\sum_{j=1}^{3}\left(\frac{S}{N_{j}}-\overline{\left(\frac{S}{N}\right)}\right)^{2}
$$

Table 4: Contribution of process parameters on the deep-drawing process.

\begin{tabular}{ccc|} 
Process parameter & Sum of squares(SS $\mathbf{i})$ & \% Contribution \\
Blank temp & 23.0826 & 84.4 \\
Die arc radius & 1.8115 & 6.6 \\
Punch Velocity & 2.4778 & 9.0 \\
\hline
\end{tabular}

The calculated value for each process parameter is given in Table 4. The percentage contribution of individual process parameter on deep drawing process can be calculated by

$$
\% \text { Contribution }=\frac{S S_{i}}{S S} \times 100
$$

The degrees of importance of each parameter considered, namely, blank temperature, die arc radius and punch velocity is given in Table 4. Blank temperature has greatest influence on the formability of AA7075 sheet with $84.4 \%$ influence followed by Punch velocity with $9.0 \%$ and die arc radius with $6.6 \%$. 
3.4 Multiple Regression Analysis (MRA): Many statistical techniques are concerned with prediction. One such technique, which is widely used, is multiple regression analysis. Regression analysis is a statistical technique used to find relationships between variables for predicting intermediate values within the range of the level. The use of a single independent variable is known as simple regression analysis, while the use of two or more independent variables is called multiple regression analysis. In this investigation, the relationship among process parameters for a given response or outcome is modelled.

Table 5: MRA Data

\begin{tabular}{ccccccc}
\hline $\begin{array}{c}\text { Blank } \\
\text { Temperature } \\
\mathbf{(}^{\mathbf{0}} \mathbf{)}\end{array}$ & $\begin{array}{c}\text { Die arc } \\
\text { radius } \\
(\mathbf{m m})\end{array}$ & $\begin{array}{c}\text { Punch } \\
\text { Velocity } \\
\mathbf{( m m} / \mathbf{s e c})\end{array}$ & $\begin{array}{c}\text { Cup height } \\
\text { (simulation) } \\
\mathbf{( m m )}\end{array}$ & $\begin{array}{c}\text { Cup height } \\
\text { (from regression } \\
\text { equation) }(\mathbf{m m})\end{array}$ & Residual & \%Residual \\
\hline 200 & 6 & 1 & 7.05 & 6.8565 & 0.1935 & 2.74 \\
200 & 9 & 2 & 5.83 & 6.3490 & -0.5190 & -8.90 \\
200 & 12 & 3 & 6.90 & 6.5794 & 0.3206 & 4.64 \\
325 & 6 & 2 & 6.50 & 6.5937 & -0.0937 & -1.44 \\
325 & 9 & 3 & 6.97 & 6.7043 & 0.2657 & 3.81 \\
325 & 12 & 1 & 10.0 & 10.1662 & -0.1662 & -1.66 \\
450 & 6 & 3 & 11.7 & 11.8015 & -0.1015 & -0.86 \\
450 & 9 & 1 & 15.4 & 15.1436 & 0.2564 & 1.66 \\
450 & 12 & 2 & 14.6 & 14.7559 & -0.1559 & -1.06 \\
\end{tabular}

The material AA 7075 which deformed under various process parameter conditions was modeled using a MRA technique. In the MRA-based approach, the dependent variable $(\mathrm{Y})$ was related to the independent variables $(\mathrm{T}, \mathrm{R}$ and $\mathrm{V})$ using both linear and nonlinear (polynomial) order regression models. The results obtained have shown that no substantial improvement is given by the linear regression so that the non-linear regression-based approach was used. Previous researchers indicated that the deformation behaviour will follow logarithmic curve for punch velocity variation. Therefore, the cup height was predicted using the following relationship:

$$
\mathrm{Y}=a_{0}+a_{1} X_{1}^{k_{1}}+a_{2} X_{2}^{k_{2}}+a_{3} \operatorname{Ln} X_{3}
$$

Where $a_{0}, a_{1}$, and $a_{2}$ are the regression coefficients, $\mathrm{k}_{1}$ and $\mathrm{k}_{2}$ are power values of regression, $\mathrm{X}_{1}, \mathrm{X}_{2}$ and $\mathrm{X}_{3}$ are the process parameters of blank temperature, die arc radius and punch velocity. The regression gives the following values of coefficients. $\mathrm{a}_{0}=5.39, \mathrm{a}_{1}=7.25 \mathrm{E}-14, \mathrm{a}_{2}=0.12, \mathrm{a}_{3}=-2.148, \mathrm{k}_{1}=5.279$ and $\mathrm{k}_{2}=1.34$.

\section{Model Plot Diagram:}

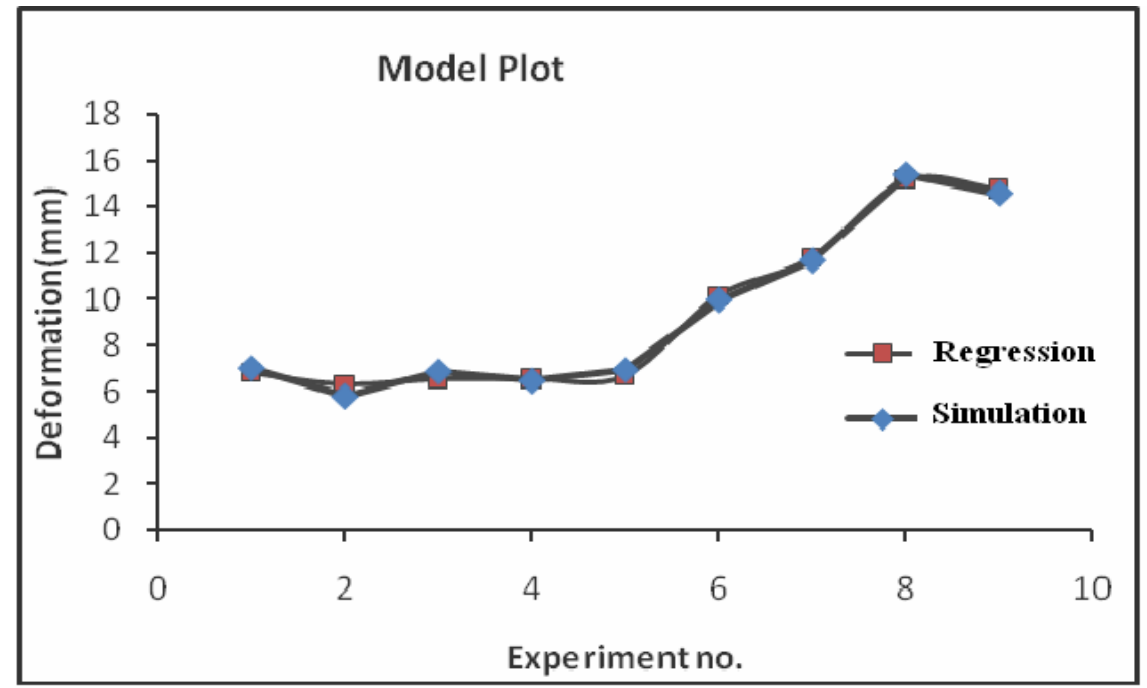

Figure 5: Diagram between Simulated and values from regression equation

Figure 5 shows the model diagram between simulated and calculated deformation values. It should be noted that the values from the simulation are almost equal to the formbability values obtained from the regression anlalysis. 


\section{Conclusion}

This paper illustrates the use of FE simulations with Taguchi design of experiments technique to determine the proportion of contribution of the important process parameters in the deep-drawing process deformation response namely blank temperature, die arc radius and punch velocity. FEM simulation in combination with Taguchi DOE technique forms an effective method to predict the influence of process parameters. The analysis of variance (Pareto Anova) was carried out to examine the influence of process parameters on the deformation of the drawing cup and their percentage contribution. The blank temperature (84.4\%) has major influence on the deep-drawing process, followed by punch velocity (9\%) and die arc radius (6.6\%). Multiple non-linear regression equation was modelled to predict the deformation at various intermediate conditions within the level range. In the cup deep drawing process, at high temperature, there exists heat transfer between tool and work piece which has not been considered in the present work and it is suggested to be an area for further study. Anova and MRA methods can provide optimal parameters, however, these parameters have to be validated by conducting experiments. This has not been considered here but suggested for further research. We have not considered blank holding force as a variable parameter but it plays critical role in product quality. Hence it is suggested to carry out further studies in this area.

\section{References}

Alexandreanu B., Sencer B.H., Thaveeprungsriporn V. and Was G.S., 2003. The effect of grain boundary character distribution on the high temperature deformation behaviour of Ni-16Cr-9Fe alloys, Acta Met, Vol. 51, pp. 3848-3851.

Davidson M.J., Balasubramanian K. and Tagore G.R.N., 2008. Experimental investigation on flow- forming of AA6061 alloy-A Taguchi approach, Journal of Materials Processing Technology, Vol. 200, No.1-3, pp. 283-287.

Davidson M.J., Balasubramanian K. and Tagore G.R.N., 2008. Modelling of Aging Treatment of Flow-Formed AA6061 Tube, Materials and Manufacturing Processes, Vol. 23, No. 5, pp. 538-542.

Davidson M.J., Balasubramanian K. and Tagore G.R.N., 2008. Surface roughness prediction of flow-formed AA6061alloy by design of experiments, Journal of Materials Processing Technology, Vol. 202, No. 1-3, pp. 41-46.

Datta S., Nandi G., Bandyopadhyay A. and Pal P.K., 2010. Parametric optimization of CNC end milling using entropy measurement technique combined with grey-Taguchi method, International Journal of Engineering, Science and Technology, Vol. 2, No. 2, pp. 1-12.

Datta S., Nandi G., Bandyopadhyay A. and Pal P.K., 2010. Optimization of CNC end milling process parameters using PCAbased Taguchi method, International Journal of Engineering, Science and Technology, Vol. 2, No. 1, pp. 92-102.

Dejmal I., Tirosh J., shirizy A. and Rubinaky L., 2002. On the optimal die curvature in deep drawing processes, International Journal of Mechanical Sciences, Vol. 44, No.6, pp. 1245-1258.

Elangovan K. and Sathiya Narayanan C., 2010. Application of Taguchi approach on investigation of formability for perforated Al 8011 sheets, International Journal of Engineering, Science and Technology, Vol. 2, No. 5, pp. 300-309.

Finch D.M., Wilson S.P. and Dorn J.E., 1946. Deep drawing aluminium alloys at elevated temperatures. Part I. Deep drawing cylindrical cups, Transactions ASM, Vol.36, pp. 254-289.

Finch D.M., Wilson S.P. and Dorn J.E., 1946, Deep drawing aluminium alloys at elevated temperatures. Part II. Deep drawing boxes, Transactions ASM, Vol.36, pp. 290-310.

Harped E.T., Worswick M.J., Finn M., Jain M. and Martin P., 2000. Numerical prediction of the limiting drawing ratio for alloy sheet, Journal of Materials Processing Technology, Vol.100, No.1-3, pp. 131-141.

Heinz A. and Haszler A., 2000. Recent development in aluminum alloys for aerospace applications, Material Science Engineering A, Vol. 280, No.1, pp. 102-107.

Huang Y. and Chen J., 1995. Influence of die arc on the formability in cylindrical cup-drawing, Journal of Materials Processing Technology, Vol. 55, No.3-4, pp. 360-369.

Li J.F., Peng Z.W., LI C.X., Chen W.J. and Zheng W.J., 2008. Mechanical properties, corrosion behaviors and microstructures of 7075 aluminium alloy with various aging treatments. Trans Non ferr Metal Soc China., Vol. 18, No. 4, pp. 755-762.

Mathivanan D., Nouby M. and Vidhya R., 2010. Minimization of sink mark defects in injection molding process - Taguchi approach, International Journal of Engineering, Science and Technology, Vol. 2, No. 2, pp. 13-22.

Park S.H; 1996. Robust Design \& Analysis for Quality Engineering, Chapman\& Hall, London.

Phadke M.S., 1989. Quality Engineering Using Robust Design, Prentice Hall, NJ, US.

Rao K.P. and Prasad Y.V.R.K., 2010. Design and simulation of laboratory scale back ward extrusion process for magnesium alloys, 24 ${ }^{\text {th }}$, AIMTDR Conference, Vizag, India, Vol. 1, pp. 17-22.

Keller C., Hug E., Retoux R. and Feaugas X., 2010. TEM study of dislocation patterns in near-surface and core regions of deformed nickel polycrystals with few grains across the cross section, Mechanics of Materials,Vol. 42, No. 1, pp. 44-54.

Shehata F., Painter M.J. and Pearce R., 1978. Warm forming of aluminium/magnesium alloy sheet, Journal of Mechanical Working Technology, Vol .2, No.3, pp. 279-291.

Taguchi G.and Konishi S., 1987. Taguchi method, orthogonal arrays and linear graphs: Tools for Quality Engineering, American Supplier Institute, pp. 35-38. 
Takuda H., Mori K. and Masuda I., 2002. Finite simulation of warm deep drawing of aluminium alloy sheet when accounting for heat conduction, Journal of Materials Processing Technology, Vol.120, No.1-3, pp. 412-418.

Toros S., Ozturk F. and Ilyas Kacar., 2008. Review of warm forming of aluminum-magnesium alloys, Journal of Materials Processing Technology, Vol.207, No.1-3, pp. 1-12.

Tetsuo N. and Fusahito Yoshida; 1999. Deepdrawbility of type 5083 aluminium-magnesium alloy sheet under various conditions of temperature and forming speed, Journal of Materials Processing Technology, Vol. 89-90, pp. 19-23.

Venkateswarlu G., Davidson M.J. and Tagore G.R.N., 2010. Finite element simulations of deep drawing of aluminium alloy sheets at elevated temperature, ARPN Journal of Engineering and Applied Sciences, Vol. 5, No. 7, pp. 93-98.

Williams J.C. and Starke Jr EA., 2003. Progress in structural materials for aerospace systems, Acta Materialia, Vol. 51, No. 19, pp. 5775-99.

Wilson D.V. 1988. Aluminium versus Steel in family car-the formability factor, Journal of Mechanical Working Technology, Vol.16, No.3, pp. 255-277.

Biographical notes

Mr. G. Venkateswarlu is a full time research scholar of Department of Mechanical engineering, National Institute of Technology, and Warangal.A.P, India. He obtainened M.Tech in Manufacturing engineering from National Institute of Foundry and Forge Technology, Ranchi. He has more than 8 years experience in teaching.

Dr. M. J. Davidson is an Asst. Professor in Mechanical Engineering Department, NITW.He got his ME in CAD/CAM from Anna University, Chennai; and $\mathrm{Ph}$.D.from NITW.His research interests are metal processing, modeling of manufacturing systems and statistical modeling.

Prof. G. R. N. Tagore is Professor in Department of Mechanical engineering; NITW. He obtained his Ph.D in manufacturing engineering from NIT Warangal and is actively doing research in the fields of welding, forming and casting. He has more than 27 years experience in teaching besides 12 years as practicing engineer. He has published more than 20 papers in National and International journals.

Received September 2010

Accepted December 2010

Final acceptance in revised form December 2010 